\title{
SISTEMA DE SUPORTE À DECISÃO PARA GESTÃO DE COMPRAS PÚBLICAS NA MODALIDADE DE REGISTRO DE PREÇOS: UM ESTUDO DE CASO DE SUPRIMENTO DE MATERIAIS NO SETOR ELÉTRICO
}

\section{DECISION SUPPORT SYSTEM FOR PUBLIC PROCUREMENT MANAGEMENT IN PRICE REGISTRY MODE: A CASE STUDY ON MATERIALS SUPPLY IN ELECTRICAL INDUSTRY}

\author{
Ricardo Santana Maués ${ }^{1}$; Ana Victoria da Costa Almeida ${ }^{2}$; André Cristiano Silva Melo ${ }^{3}$; Denilson \\ Ricardo de Lucena Nunes ${ }^{4}$; Vitor William Batista Martins ${ }^{5}$ \\ ${ }^{1}$ Universidade do Estado do Pará - UEPA - Belém, PA - Brasil \\ maues.engenharia@gmail.com \\ ${ }^{2}$ Universidade do Estado do Pará - UEPA - Belém - PA - Brasil \\ anavictoriaalmeida@yahoo.com.br \\ ${ }^{3}$ Universidade do Estado do Pará - UEPA - Belém - PA - Brasil. \\ acsmelo@yahoo.com.br \\ ${ }^{4}$ Universidade do Estado do Pará - UEPA - Belém - PA - Brasil \\ denilson.lucena@gmail.com \\ ${ }^{5}$ Universidade do Estado do Pará - UEPA - Belém - PA - Brasil \\ vitor_engenharia@hotmail.com
}

\section{Resumo}

A função compras é estratégica para as empresas já que pode promover redução de custos no processo de suprimento e permitir que os materiais utilizados na produção estejam sempre disponíveis no momento e em quantidade desejados. Como consequência de uma gestão de compras adequada, as empresas podem aumentar sua competitividade com essa potencial redução de custos e aumento da eficiência em seu suprimento. As empresas do setor elétrico no Brasil, em virtude da recente crise energética, dentre outros motivos, buscam redução de gastos com a geração e transmissão de energia para tornar o setor mais competitivo no país. Neste contexto, a função compras pode contribuir, sobretudo, na gestão adequada dos suprimentos nesse setor que, algumas vezes, encontra dificuldades para manter o fornecimento contínuo de energia, o que resulta em multas e perda da qualidade no serviço prestado ao consumidor. Assim, este artigo propõe um sistema de suporte à decisão para gestão de compras públicas em regime de Registro de Preços. Para tanto, utilizou-se como objeto de estudo uma empresa do setor elétrico situada no estado do Pará. O sistema proposto corresponde a um módulo computacional adicionado ao sistema usado na empresa, tendo por objetivo auxiliar o gerenciamento do ressuprimento de materiais através do controle da vigência dos processos de compras, bem como das informações pertinentes à execução de tais processos. A partir da implantação do sistema proposto na empresa estudada, foi possível observar melhorias, como a redução de tempo e custos na geração e gestão dos processos de compras.

Palavras-chave: gestão de compras; compras públicas; registro de preços; setor elétrico 


\section{Introdução}

O ambiente competitivo em que as organizações estão inseridas, as mudanças no sistema de produção e a introdução de novas tecnologias conduzem às empresas a responderem de forma rápida aos apelos e necessidades do ambiente externo, em busca de aumentos de produtividade e redução de custos na gestão de seus negócios. Assim, as organizações têm que se adaptar ao ambiente externo e se capacitar para um trabalho de planejamento visando a projeções futuras, considerando o cliente com suas exigências e necessidades, o mercado, seus colaboradores e produtos.

Neste contexto, Davenport (1994) afirma que a inovação de processos é um veículo fundamental para a implementação de estratégias de redução de custos, aumento da velocidade nos processos e satisfação do cliente, tornando-se uma importante fonte de vantagem competitiva para as organizações. Desta forma, um programa de redução de custos e aumento de produtividade deve ser apresentado não como uma crítica ao trabalho que vem sendo executado, mas como um recurso, uma nova técnica, ou mesmo um sistema ou procedimento que só agora foi necessário e está sendo colocado à disposição da empresa. Para o bom funcionamento das empresas, é de fundamental importância que seus insumos e materiais diversos estejam disponíveis na quantidade certa, no local certo e na hora certa (BALLOU, 2001). Para tal, faz-se necessário uma efetiva gerência de materiais, que se analisem todas as etapas envolvidas no ressuprimento da empresa, para que se possam identificar possíveis gargalos e irregularidades, desenvolvendo alternativas para solucionálos e melhorar continuamente o processo.

A eficiência na disponibilidade de materiais também é relevante nas atividades de geração e distribuição de energia elétrica, sobretudo em momentos de crise energética, como ocorrido recentemente. Segundo publicação da VEJA (2012), no Brasil, as hidrelétricas são responsáveis por quase $70 \%$ (setenta) da geração de energia elétrica e os reservatórios que abastecem usinas tem apresentado níveis insignificantes, por conta da seca no Sudeste e Centro Oeste, com um nível médio abaixo de 18\%. Portanto, há uma necessidade de redução dos gastos com a geração e transmissão de energia, visando ao aumento da competitividade. Para tanto, se faz necessário um gerenciamento correto dos materiais que dão suporte às operações das empresas de energia elétrica, gerando assim uma redução de custos operacionais tanto no aspecto do investimento direto quanto na redução do pagamento de multas em caso de interrupção no fornecimento de energia.

A busca pela efetividade na gestão de estoques mostra-se cada vez mais necessária para o setor elétrico, visto que ele apresenta um papel fundamental e estratégico como o alicerce para o crescimento e desenvolvimento de quaisquer atividades no Brasil. Segundo a Projeção da Demanda de Energia Elétrica 2012-2021, a projeção de demanda elétrica entre 2011-2021, para o país, é de 
um crescimento de 5,8\%, 4,5\% e 3,8\% ao ano, respectivamente, para as classes comercial, residencial e industrial. Fato este que atrai a atenção, dada a sua importância (PDEE, 2013).

Entretanto, manter o nível satisfatório de investimento em recursos materiais é um desafio também no âmbito das empresas públicas que, nesse caso, deve seguir várias exigências e especificidades da legislação vigente, por exemplo, a Lei de Licitações e Contratos Administrativos (Lei 8.666 de 21 de junho de 1993), que rege as normas para aquisição de bens por empresas públicas. No Decreto $n^{\circ} 7.892 / 13$, o Sistema de Registro de Preço, previsto no Art.15 da Lei 8.666/93, apresenta-se como uma possibilidade de alternativa para a complexidade de aquisição por parte dessas empresas, em decorrência da sua praticidade e conveniência para solicitação dos materiais contratados de forma fracionada, de acordo com as necessidades da empresa (BRASIL, 2013).

No que se refere à empresa objeto de estudo, após o mapeamento e análises de todas as etapas no processo de reposição de materiais de um dos seus almoxarifados, verificou-se a dificuldade em realizar uma gestão eficiente dos estoques, devido à complexidade na legislação referente à licitação ou à falta de um software capaz de abranger todas as etapas do processo de ressuprimento dos materiais relacionados. Portanto, o desenvolvimento deste artigo teve por objetivo, promover uma alternativa à melhoria do processo de ressuprimento de materiais em uma empresa do setor elétrico, potencializando a utilização do Sistema de Registro de Preço (SRP), a partir do desenvolvimento de um módulo computacional que atuasse integrado ao sistema de gestão empresarial utilizado na empresa - Sgestor.

Assim, o presente artigo foi estruturado em 4 seções de forma que: na Seção 2 encontram-se os conceitos de logística, cadeia de suprimentos e compras públicas; na Seção 3, foram descritos os procedimentos metodológicas utilizados nesta pesquisa; na Seção 4 apresentam-se os problemas identificados na empresa objeto deste estudo, bem como, o sistema proposto e as melhorias observadas. As considerações finais estão reunidas na Seção 5.

\section{Referencial teórico}

\subsection{Logística e cadeia de suprimento}

Segundo Chopra \& Meindl (2003), a cadeia de suprimentos pode ser entendida como um conjunto de etapas envolvidas, direta ou indiretamente, na produção de bens e/ou serviços e no atendimento do pedido de um cliente. Bowersox, Closs e Cooper (2007) afirmam que, para muitos gestores, o termo Cadeia de Suprimentos subentende-se uma proposta de novos arranjos comerciais, formados com o intuito de melhorar a competitividade, uma rede de relações comerciais altamente eficientes e eficazes, com o objetivo de melhorar a eficiência e eliminar o trabalho duplicado e 
improdutivo.

Outro conceito importante a ser abordado quando se trata de logística e a cadeia de suprimentos, é o de estoques. De acordo com Slack, Chambers e Johnston (2009), estoques são definidos como uma acumulação de forma armazenada de recursos materiais em um sistema de transformação. Para Ballou (2001), estoques são usados para melhorar a coordenação da ofertademanda e para reduzir os custos totais.

Dentro de uma empresa, as necessidades de estoques, segundo Bowersox, Closs e Cooper (2007), estão diretamente relacionadas à rede de instalações e ao nível desejado de serviço ao cliente. Outras razões para utilização de estoques, segundo Ballou (2001), são:

- Para reduzir custos de transporte e de produção;

- Para auxiliar no processo de produção;

- Para ajudar no processo de marketing.

Em resumo, os estoques apresentam-se como de fundamental importância para o bom desempenho de uma organização, sendo extremamente necessário definir as estratégias de estoques dentro da empresa.

Ressalta-se que qualquer recurso armazenado em forma de estoques representa custos para empresa, podendo ser: custos de compras, de alocação, de oportunidades, entre outros, e seu valor pode variar em função da sua quantidade e da atividade da empresa, em especial, naquelas onde a armazenagem é o propósito principal da organização.

De acordo com Slack, Chambers e Johnston (2009), alguns custos de estoques estão diretamente relacionados ao tamanho do lote e podem ser classificados como:

a) Custo de colocação do pedido: Está relacionado aos custos das tarefas de escritório, de arranjo para entrega, de pagar o fornecedor pela entrega e os custos gerais para manter todas as informações;

b) Custo de desconto de preços: Diz respeito ao ato de barganhar preços em função de grandes quantidades solicitadas, o que não ocorre para pequenas quantidades;

c) Custo de falta de estoques: Dependendo da etapa em que esses estoques estejam inseridos, pode acarretar em tempo ocioso no processo produtivo (para consumidores internos), ou até a troca de fornecedor (para consumidores externos);

d) Custo de capital de giro: Se refere ao fundo de dinheiro necessário para manter os estoques no lapso de tempo entre pagar os fornecedores e receber pagamento dos clientes;

e) Custo de armazenagem: Está diretamente relacionado à infraestrutura necessária para armazenagem física dos bens. Armazém com iluminação, climatização, locação etc.;

f) Custo de obsolescência: Está vinculado ao risco de armazenagem de grandes quantidades de materiais que podem se deteriorar, como alimentos, ou se tornar obsoletos, em casos de mudança 
na moda, por exemplo;

g) Custo de ineficiência de produção: Decorre da dificuldade de verificação da completa extensão de problemas dentro da produção em função dos altos níveis de estoque, segundo a filosofia Just in time.

Desta forma, a gestão eficiente dos estoques está diretamente relacionada à decisão de quanto comprar em cada momento da identificação da necessidade de materiais, sempre levando em consideração trade-off de custos. Segundo Slack, Chambers e Johnston (2009), uma alternativa seria manter baixos, ou zero, os níveis de estoques e comprar cada item somente quando necessário, tendo como vantagem, a economia com armazenagem e disponibilidade de capital para compras, visto que compraria em pequenas quantidades e, como desvantagem, a necessidade de efetuar várias compras, desperdiçando muito tempo e esforço.

Por outro lado, segundo o mesmo autor, há a possibilidade de comprar em larga escala, obtendo vantagens na barganha de preço de compra, redução dos tempos de compra e evitando a falta de material, o que por outro lado elevam os custos com armazenagem e de capital imobilizado para compras, que poderiam estar sendo aplicados em outros investimentos e rendendo juros. Desta forma, entende-se que encontrar o equilíbrio entre esses dois extremos é fundamental para minimizar os custos totais e o esforço envolvido nas compras.

Outro aspecto importante a ser considerado, refere-se ao Tempo de reposição ou Lead time que, segundo Dias (2010), é o tempo gasto verificando os estoques que precisam ser repostos até a chegada efetiva do material para o almoxarifado da empresa. Ainda segundo o mesmo autor, este tempo pode ser dividido em três etapas:

a) Tempo de emissão do pedido: Envolve o tempo desde a verificação da necessidade de material dentro da empresa, sua emissão e chegada ao fornecedor;

b) Tempo de preparação do pedido: Diz respeito ao tempo que o fornecedor precisa para fabricar os produtos, separar, faturar e embalar para transporte;

c) Tempo de transporte: tempo compreendido no transporte da mercadoria do fornecedor até a empresa solicitante.

$\mathrm{Na}$ administração pública, é fundamental mensurar não apenas quanto e quando pedir, mas também o tempo necessário para que a modalidade licitatória selecionada ocorra, de modo que a correta programação de todo o lead time de ressuprimento seja considerada.

\subsection{Compras públicas}

Segundo a Constituição Federal de 1988, em seu Artigo 37 (caput), a licitação é a maneira formal pela qual a administração pública direta, indireta ou funcional, de qualquer das esferas de poder da União, dos Estados, do Distrito Federal e dos Municípios, ficará obrigada a se utilizar para 
aquisição de produtos, bens e/ou contratação de serviços, de maneira a garantir os princípios da legalidade, impessoalidade, moralidade, publicidade e eficiência (BRASIL, 1988). Para regulamentar este artigo, foi criada a Lei das Licitações (Lei 8.666/93), conforme exposto por Pereira Junior (2007, p.13):

(...) A Lei 8.666/93 vem atender à previsão do art. 37, XXVI, da Constituição Federal de 1988, que impõe à Administração Pública fazer uso, como princípio e regra geral, da licitação para selecionar aquele a quem contratará obras, serviços, compras e alienações.

A licitação, portanto, determinará as bases legais para as relações comerciais entre a Administração Pública e as empresas em geral. Levando-se em consideração que a Lei das Licitações vem para estabelecer as regras gerais para contratação de empresas interessadas em negociar propostas e preços com a Administração Pública, sem ferir os princípios constitucionais, é de extrema importância relatar o Artigo $3^{\text {a }}$ desta lei:

A licitação destina-se a garantir a observância do princípio constitucional da isonomia, e a selecionar a proposta mais vantajosa para a Administração e será processada e julgada em estrita conformidade com os princípios básicos da legalidade, da impessoalidade, da moralidade, da igualdade, da publicidade, da probidade administrativa, da vinculação ao instrumento convocatório, do julgamento objetivo, e dos que lhes são correlatos. (Brasil, 2013,s.p.).

\subsubsection{O Sistema de Registro de Preço (SRP)}

Por meio do Decreto 3.931 de 19 de Setembro de 2001, foi definido o Sistema de Registro de Preço como:

Sistema de Registro de Preço - SRP - conjunto de procedimentos para registro formal de preços relativos à prestação de serviços e aquisição de bens, para contratações futuras. (Brasil, 2001, s.p.).

Para uma melhor compreensão do significado de determinados termos dessa normatização, Fernandes (2008, p.30) sistematiza o tema da seguinte maneira:

Sistema de Registro de Preço é um procedimento especial de licitação que se efetiva por meio de uma concorrência ou pregão sui generis, selecionando a proposta mais vantajosa, com observância do princípio da isonomia, para eventual e futura contratação pela Administração.

Dentre suas peculiaridades, o SRP apresenta a flexibilidade para a Administração Pública promover, ou não, as aquisições dos produtos ou serviços, ou seja, ela não está obrigada a comprar, e quando assim o fizer, será de acordo com as suas necessidades diretas (e não somente estimadas sem fundamento algum) e disponibilidade orçamentária, comparativamente à forma de contratação utilizada pelo setor privado, sem deixar de garantir a plena eficácia dos princípios constitucionais da legalidade e isonomia.

\subsection{Setor elétrico}

Souza Junior (2011) afirma que a energia elétrica é utilizada por consumidores, comércio e indústria, sendo um recurso que representa um importante desenvolvimento da qualidade de vida. 
Pelo fato de não poder ser armazenada em quantidades consideráveis, a energia elétrica deve ser fornecida de maneira contínua, pois precisa estar disponível à medida que for solicitada. Em 2004, foi sancionada a Lei 10.848, a qual estabeleceu bases para o novo modelo do setor elétrico, garantindo a desverticalização do setor, que organizou as empresas nos segmentos de geração, transmissão e distribuição de energia, com incentivo à competição dos segmentos de geração e comercialização, e manteve sob regulação os segmentos de distribuição e transmissão.

O modelo extinguiu o Mercado Atacadista de Energia Elétrica (MAE) e, em seu lugar, alocou a Câmara de Comercialização de Energia Elétrica (CCEE) para atuar na contabilização e liquidação das transações que acontecem em dois distintos ambientes de contratação: o Ambiente de Contração Regulada (ACR) e o Ambiente de Contratação Livre (ACL). O primeiro ambiente de contratação (ACR), composto pelo conjunto de todas as distribuidoras, realiza leilões de energia para consumidores cativos, havendo uma distinção entre leilões de energia existente ("energia velha") e leilões de energia oriundas da expansão de sistema ("energia nova"). O segundo ambiente de contratação (ACL) é composto por geradores e produtores independentes que, livremente, vendem energia para consumidores livres (Brasil e MME apud Almeida, 2008).

\section{Procedimentos metodológicos}

De modo a alcançar o objetivo proposto para este artigo, foram desenvolvidos os seguintes procedimentos metodológicos. Primeiramente, realizou-se uma análise prévia do ambiente de ressuprimento na qual a empresa atua, tanto a nível micro (estrutura física, estrutura organizacional, funcionários envolvidos etc.) quanto ao nível macro (setor elétrico regional e nacional). O objetivo dessa análise foi compreender a relação entre o processo de ressuprimento dos estoques e o funcionamento global da empresa, assim como com seu posicionamento estratégico no ambiente do setor elétrico brasileiro.

Fez-se importante, ainda, a pesquisa bibliográfica, abordando tópicos básicos à composição do conhecimento necessário ao desenvolvimento da pesquisa, a saber, o setor elétrico, a legislação vigente sobre compras públicas, em especial o SRP; além de pesquisas em documentos internos da empresa objeto de estudo.

Foram efetuadas entrevistas não estruturadas com os gerentes e empregados (assistentes e auxiliares) envolvidos no processo de aquisição, tanto do setor de aquisição, como do almoxarifado, a fim de tomar ciência das especificidades de cada etapa produtiva, das possíveis deficiências e dificuldades enfrentadas na rotina de trabalho, no que se refere ao gerenciamento e reposição de materiais da organização, entre outras informações pertinentes ao objetivo do projeto.

Posteriormente, foram coletados os dados do sistema Sgestor e efetuado o mapeamento do processo de ressuprimento da empresa, desde a verificação da disponibilidade de determinado 
material (nível de estoques), seguindo pela requisição de compra (RC), feita pelo almoxarifado, até a aquisição dos materiais, feita pelo setor de compras, e, posteriormente, entrega dos itens solicitados ao almoxarifado. Foram colhidos, nesse procedimento, dados históricos de relatórios de solicitação de materiais, do preenchimento manual dos Documentos Formais de Compra (DFC), Tabelas de máximos e mínimos, Comunicação Interna - CI, Atas de Registro de Preço (ARP) e Requisições de Compras (RC), considerando apenas as aquisições feitas por Sistema de Registro de Preço (SRP), foco deste estudo.

Em seguida, procedeu-se à análise dos dados e informações obtidas, as quais deram suporte para a implantação da ferramenta proposta.

\section{Resultados e análises}

\subsection{Problemas identificados nos processos de suprimento}

Constatou-se que a administração de materiais da empresa objeto deste estudo, não possuía um controle gerencial eficiente para o processo de compras. Em virtude disso, alguns inconvenientes ocorriam, como perdas de capital em estoques por falhas de monitoramento; perdas de prazos de vigência de algumas ARP, o que resultava na demora na aquisição de alguns materiais; falta de registro do tempo médio para o processo de geração das ARP, o que possibilitaria a antecipação dos procedimentos antes do término do prazo de vigência da anterior; um processo para aquisição por SRP e geração de uma ARP que resultava em perda de tempo e mão de obra associada ao preenchimento manual de alguns documentos (Documento Formal de Compras - DFC, Tabelas de Máximos e Mínimos e Comunicação Interna - CI), pois as informações eram coletadas de diversas fontes, tornando o processo mais demorado e suscetível a erros.

Vale ressaltar que foi observado um importante agravante na eficiência do processo de suprimento, pois a tramitação dos processos ocorria de forma manual, onde pastas eram transportadas manualmente por diversos setores, para que, em cada um desses, fosse realizada a atividade cabível e necessária. Como consequência, ocorria a perda de documentos durante suas tramitações.

Dessa forma, concluiu-se que todo o desperdício de tempo observado, bem como os erros no preenchimento dos processos, poderiam ser evitados se houvesse o gerenciamento informatizado dos prazos de vigência das atas e as quantidades remanescentes de cada item relacionado. Como consequência, seria possível calcular o lead time real de ressuprimento e, assim, antecipar a elaboração de novas ARP sem que a empresa corresse riscos de falta de estoques.

\subsection{Sistema proposto}


A partir da coleta e análise dos dados, foi estruturado um briefing ${ }^{1}$ para o desenvolvimento de módulo informacional integrado ao Sgestor, a ser implantado pela própria empresa desenvolvedora e responsável pelo Sgestor. Destaca-se que o sistema proposto foi testado na empresa, por meio de software, e sofreu algumas adequações, antes de ser implantado. Estes testes foram acompanhados continuamente, a fim de constatar sua exequibilidade e consonância com o briefing exposto. A cada teste apresentado, foram feitas reuniões com os gerentes e empregados responsáveis pelos setores diretamente envolvidos (Aquisição e Almoxarifado), para validar os resultados apresentados e, caso necessário, sugerir/relacionar ajustes para sua implementação final.

A partir da validação final, a nova ferramenta foi apresentada a toda a empresa e entrou em fase de implementação. Suas principais funcionalidades foram informatizar os procedimentos de aquisição por SRP e simplificar o gerenciamento das ARP que constituem a base para agilizar o ressuprimento dos materiais. Depois de implementada, a ferramenta tornou o preenchimento mais dinâmico, pois a partir desta, foi criado um banco de dados com várias informações dos materiais (códigos Siasg e do material, descrição detalhada e resumida, unidade, entre outras), que antes precisavam ser inseridas manualmente, uma a uma. A partir de um mecanismo automático de busca do material ou serviço, baseado na descrição parcial ou no seu código, apenas a simples seleção do material desejado (por meio de uma lista automática) permitiu acessar todas as demais informações deste material e preencher automaticamente todos os campos necessários, restando ao requisitante apenas inserir as três cotações dos fornecedores, a quantidade desejada do material e suas quantidades máximas e mínimas por solicitação.

Após algum tempo de utilização da nova ferramenta, foi possível constatar uma considerável melhora no processo de ressuprimento de materiais, com possibilidade de reduções de capital imobilizado com estoques (ver Tabela 1). Tais valores foram obtidos a partir da análise dos valores totais, registrados em 22 ARP, e dos contratos imediatos, firmados logo após a vigência dessas ARP, para suprir as necessidades reais e urgentes da empresa, considerando os anos de 2012 e 2013.

Tabela 1- Valor das ARP, dos contratos e estoque evitado

\begin{tabular}{c|c|c|c}
\hline Ano & R\$ Registrado em ARP & R\$ Contratos Imediatos & R\$ Estoque evitado \\
\hline 2012 & $\mathrm{R} \$ 871.786,12$ & $\mathrm{R} \$ 281.375,67$ & $\mathrm{R} \$ 590.410,45$ \\
\hline 2013 & $\mathrm{R} \$ 1.265 .604,43$ & $\mathrm{R} \$ 308.857,13$ & $\mathrm{R} \$ 956.747,29$ \\
\hline Total & $\mathrm{R} \$ 2.137 .390,55$ & $\mathrm{R} \$ 590.232,80$ & $\mathrm{R} \$ 1.547 .157,74$ \\
\hline
\end{tabular}

Fonte: autores (2015)

A partir das potenciais economias apresentadas na Tabela 1, ficou claro que a nova ferramenta poderá impactar em ganhos significativos em termos de desempenho dos processos de compras por SRP, já que seu uso resultou em reduções de compras e aquisições em caráter de

\footnotetext{
${ }^{1}$ Briefing: é um conjunto de informações, uma coleta de dados para o desenvolvimento de um trabalho.
} 
urgência.

\subsubsection{Melhorias observadas}

A implantação do módulo informacional para SRP possibilitou melhorias à gestão de ressuprimentos de materiais e componentes da empresa. Tais melhorias foram verificadas por meio dos seguintes resultados:

a) Do ponto de vista gerencial

- Todas as modalidades e procedimentos licitatórios, para selecionar fornecedores de obras e serviços, compras e alienações para a Administração Pública, foram integrados, facilitando assim o seu gerenciamento;

- Foram viabilizados o Mapeamento e o controle dos tempos envolvidos em cada etapa do processo licitatório, de acordo com a modalidade utilizada, atividades antes impossíveis, visto que partes importantes do processo eram executadas manualmente;

- Melhor gerenciamento sobre os prazos de vigência das ARP, com base no levantamento mais preciso dos tempos para a realização dos contratos, em especial pelo SRP, o que possibilitou iniciar novas licitações e contratações antes do fim da vigência destas ARP, e no saldo de materiais e/ou serviços ainda disponíveis do total estabelecido no contrato, garantindo o contínuo fornecimento de materiais, de acordo com demandas da Administração;

b) Do ponto de vista operacional

- Aumento da frequência de utilização do SRP para contratações da Administração Pública, visto que os procedimentos se tornaram mais fáceis, rápidos e eficientes, inclusive no que se refere a criação e gerenciamento das ARP;

- Redução dos estoques, do alto valor de capital imobilizado, dos espaços de armazenamento e da mão de obra necessários para acondicionamento e manutenção destes estoques, pois, com a utilização das ARP, evitou-se o emprego do Pregão Eletrônico (PE) convencional e a, consequente, aquisição de materiais de uma só vez.

\section{Considerações finais}

A ferramenta criada caracterizou-se como um módulo computacional integrado ao sistema SGestor, utilizado para a compras de bens e contratação de serviços por meio das modalidades licitatórias, considerando apenas os procedimentos do SRP. A partir dos resultados potenciais gerados (reduções de tempos, de riscos de perdas, de erros e de retrabalhos, e de custos), foi constatada a viabilidade de sua utilização, além de ser de fácil utilização e adaptação, podendo ser utilizada por qualquer requisitante ou em qualquer outra área da empresa.

Outro aspecto a ser destacado refere-se à extrema importância da utilização do SRP, como 
estratégia para redução de valores imobilizados em estoques. Desta forma, esta pesquisa apresentou-se importante como alternativa para a redução de custos de estoques, além de reduzir os custos de mão de obra (Homem x Hora) necessária para gerenciar uma quantidade absurda de materiais que seriam estocados no almoxarifado.

Levando-se em conta que os processos de aquisição pública são baseados na legislação e que esta pode sofrer alterações, sempre haverá a possibilidade de validar os novos modelos e adequações, sempre que estes sofrerem mudanças, comparando os tempos, a qualidade e a praticidade dos processos antes e depois das mesmas.

Com isso, ficou claro que a utilização da nova ferramenta contribuiu positivamente para o processo de compras e, consequentemente, para o melhor desempenho da empresa.

Como pesquisas futuras, sugere-se efetuar pesquisas mais aprofundadas na legislação vigente, de modo a potencializar a inclusão de uma variedade ainda maior de materiais que possam ser adquiridos por SRP, de modo a potencializar ainda mais as reduções nos valores atualmente imobilizados em estoques, ou seja, recomenda-se uma pesquisa na legislação específica sobre quais materiais podem ainda ser adquiridos por SRP e incluídos em ARP, fazendo com que estes deixem de ser comprados e estocados de uma só vez e em grandes quantidades, passando a serem solicitados somente de acordo com as demandas reais.

Outro aspecto que não contemplado neste estudo refere-se à gestão dos contratos gerados, quer por SRP quer por outras modalidades de licitação. Tal iniciativa, certamente, facilitaria o levantamento consistente de informações para avaliação de fornecedores, considerando prazos de entregas dos materiais solicitados, além de contribuir para a formação de um histórico de compras.

Informações fundamentais à melhor gestão do processo de ressuprimentos, como lote econômico de compras, estoques de segurança e quantidades máximas e mínimas, entre outras, não foram abordados com profundidade nesta pesquisa, uma vez que ainda foram estipulados de acordo com a percepção dos requisitantes. Neste sentido, é fundamental executar um estudo completo sobre estes indicadores, para identificar os reais valores de cada parâmetro, tornando mais efetiva a contribuição do recurso informação para melhoria no sistema de aquisição por SRP.

\section{Abstract}

The procurement function is strategic for companies since it can promote cost reduction in the supply processes and it allows materials used in production to be always available at the desired time and quantity. As a result from a proper procurement management, companies can increase their competitiveness with potential cost savings and increased efficiency in supply processes. Due to the recent energy crisis, Brazilian companies in the electrical industry have sought to reduce spends on power generation and transmission processes to make this industry more competitive. In this context, the procurement process may contribute, especially in proper supply management in this industry, which sometimes finds difficulties to maintain energy continuous supply, resulting in fines and losses of quality in the customer service. Therefore, this paper proposed a decision 
support system for public procurement management based on price registry system in an electrical industry company located in the State of Para. This system corresponds to a computational module integrated to the system already used in the company, with the objective of assisting the management of materials replenishment through effectiveness control of the procurement process and considering the relevant information regarding such processes. After implementation of the proposed system, it resulted in improvements such as time and cost reduction in the generation and management of procurement processes.

Keywords: procurement management; public procurement; price registry; electrical industry.

\section{Referências}

ALMEIDA, José Álvaro Jardim De. P\&D no Setor Elétrico Brasileiro: Um estudo de caso na companhia hidro elétrica do São Francisco. 2008. 99 f. Dissertação (Mestrado) - Curso de Economia, Universidade Federal De Pernambuco, Recife, 2008.

BALLOU, R. H. Gerenciamento da cadeia de suprimento: planejamento, organização e logística empresarial. 4. ed. Porto Alegre: Bookman, 2001.

BOWERSOX, D. J.; CLOSS, D. J.; COOPER, M. B. Gestão da Cadeia de Suprimento. Rio de Janeiro: Elsevier, 2007. 442p.

BRASIL. Constituição (1998). Constituição da República Federativa do Brasil. Brasília,DF: Senado, 1988.

BRASIL. Decreto no 7.892, de 23 de janeiro de 2013. Disponível em: <

http://www.planalto.gov.br/ccivil_03/_Ato2011-014/2013/Decreto/D7892.htm>. Acesso em: 7 jun. 2013

BRASIL. Decreto no 3.931, de 19 de setembro de 2001. Disponível em: <

http://www.planalto.gov.br/ccivil_03/decreto/2001/D3931htm.htm>. Acesso em: 11 jun. 2013

BRASIL. Lei n $\mathbf{0}$ 8.666, de 21 de junho de 1993. Disponível em: <

http://www.planalto.gov.br/ccivil_03/leis/18666cons.htm>. Acesso em: 07 mai. 2013

BRASIL. Lei n $\mathrm{n}^{\circ}$ 12.783, de 11 de janeiro de 2013. Disponível em: < http://www.planalto.gov.br/ccivil_03/_ato20112014/2013/lei/L12783.htm>. Acesso em: 10 mai. 2013

BRASIL. Medida provisória nº 579, de 11 de setembro de 2012. Disponível em: < http://www.planalto.gov.br/ccivil_03/_ato2011-2014/2012/mpv/579.htm>. Acesso em: 10 mai. 2013

CCEE. Câmara de Comercialização de Energia Elétrica. Disponível em:

<http://www.ccee.org.br/portal/faces/pages_publico?_afrWindowId=194x0w45yp_1\&_afrLoop=150072961831000\&_ afrWindowMode=0\&_adf.ctrl-state=194x0w45yp_4 >. Acesso em: 07 mai. 2013

DIAS, M.A.P. Administração de materiais: uma abordagem logística. 5º ed. São Paulo (SP): Atlas, 2010.

EPE. Empresa de Pesquisa Energética. Disponível em: <

http://www.epe.gov.br/acessoainformacao/Paginas/institucional.aspx>. Acesso em: 07 mai. 2013

FERNANDES, J. U. J. Sistema de registro de preço e pregão presencial e eletrônico. 3 ed. rev., atual. e ampl. Belo Horizonte: Fórum, 2008.

MINISTÉRIO DE MINAS E ENERGIA (MME). Balanço Energético Nacional (BEN)- 2012. Brasília, 2012. Empresa de Pesquisa Energética. Rio de Janeiro: EPE, 2012.

MME - MINISTÉRIO DE MINAS E ENERGIA (Brasil). Competências. Disponivel

em:<http://www.mme.gov.br/mme/menu/acesso_a_informacao/institucional/competencias.html>. Acesso em: 18 maio 2013.

PDEE. Projeção da Demanda de Energia Elétrica 2012-2021. Disponível em:

<http://www.epe.gov.br/mercado/Documents/S\%C3\%A9rie\%20Estudos\%20de\%20Energia/20120104_1.pdf>. Acesso em: 08 mai. 2013. 
PEREIRA JUNIOR, J.T. Comentários à lei das licitações e contratações da administração pública. 7. ed. rev., atual. e ampl. Rio de Janeiro: Renovar, 2007.

SITE DA EMPRESA. 2013. Acesso em: 22 out. 2013.

SOUZA JUNIOR, E. C. Manutenção da qualidade de energia elétrica. 2011. 100 f. Relatório de Estágio Curricular (Técnico) - Curso de Técnico em Eletrotécnica, Departamento de Processos, Controles E Sistemas Eletro-eletrônicos, Instituto Federal De Educação Ciência \& Tecnologia De Pernambuco, Recife: [s.n], 2011.

SLACK, N.; CHAMBERS, S.; JOHNSTON, R. Tradução: Henrique Luiz Corrêa. Administração da Produção. 3 ed. São Paulo: Atlas, 2009.

\section{Dados dos autores}

Nome completo: Ricardo Santana Maués

Filiação institucional: Universidade do Estado do Pará, UEPA

Departamento: Engenharia de Produção

Função ou cargo ocupado: Estudante de Engenharia de Produção

Endereço completo para correspondência: Travessa Enéas Pinheiro, 2626. Belém - PA - Brasil Fone: (55) 91 3276-4011/3131-1907

E-mail: maues.engenharia@gmail.com

Nome completo: Ana Victoria da Costa Almeida

Filiação institucional: Universidade do Estado do Pará, UEPA

Departamento: Engenharia de Produção

Função ou cargo ocupado: Estudante de Engenharia de Produção

Endereço completo para correspondência: Travessa Enéas Pinheiro, 2626. Belém - PA - Brasil

Fone: (55) 91 3276-4011/3131-1907

E-mail: anavictoriaalmeida@yahoo.com.br

Nome completo: André Cristiano Silva Melo

Filiação institucional: Universidade do Estado do Pará, UEPA

Departamento: Engenharia de Produção

Função ou cargo ocupado: Professor Dr. em Engenharia de Produção, e Coordenador dos laboratórios CONCEPT e NILO

Endereço completo para correspondência: Travessa Enéas Pinheiro, 2626. Belém - PA - Brasil

Fone: (55) 91 3276-4011/3131-1907

E-mail: acsmelo@yahoo.com.br 
Nome completo: Denilson Ricardo de Lucena Nunes

Filiação institucional: Universidade do Estado do Pará, UEPA

Departamento: Engenharia de Produção

Função ou cargo ocupado: Professor Dr. em Engenharia de Produção.

Endereço completo para correspondência: Travessa Enéas Pinheiro, 2626. Belém - PA - Brasil

Fone: (55) 91 3276-4011/3131-1907

E-mail: denilson.lucena@ibest.com.br

\section{Nome completo: Vitor William Batista Martins}

Filiação institucional: Universidade do Estado do Pará, UEPA

Departamento: Engenharia de Produção

Função ou cargo ocupado: Professor Ms. em Engenharia de Produção.

Endereço completo para correspondência: Travessa Enéas Pinheiro, 2626. Belém - PA - Brasil Fone: (55) 91 3276-4011/3131-1907

E-mail: vitor_engenharia@hotmail.com

Submetido em: 30-06-2015

Aceito em: 14-09-2015 